Article

\title{
Poly(propylene 2,5-thiophenedicarboxylate) vs. Poly(propylene 2,5-furandicarboxylate): Two Examples of High Gas Barrier Bio-Based Polyesters
}

\author{
Giulia Guidotti ${ }^{1}$, Michelina Soccio ${ }^{1}$, Nadia Lotti ${ }^{1, *(\mathbb{D})}$, Massimo Gazzano ${ }^{2}$ (D), \\ Valentina Siracusa ${ }^{3, * \text { (ID) and Andrea Munari }}{ }^{1}$ (iD) \\ 1 Department of Civil, Chemical, Environmental and Materials Engineering, University of Bologna, \\ Via Terracini 28, 40131 Bologna, Italy; giulia.guidotti9@unibo.it (G.G.); m.soccio@unibo.it (M.S.); \\ andrea.munari@unibo.it (A.M.) \\ 2 Organic Synthesis and Photoreactivity Institute, ISOF-CNR, Via Gobetti 101, 40129 Bologna, Italy; \\ massimo.gazzano@isof.cnr.it \\ 3 Department of Chemical Science, University of Catania, Viale A. Doria 6, 95125 Catania, Italy \\ * Correspondence: nadia.lotti@unibo.it (N.L.); vsiracus@dmfci.unict.it (V.S.); Tel.: +39-051-209-0354 (N.L.); \\ +39-338-727-5526 (V.S.)
}

Received: 30 June 2018; Accepted: 13 July 2018; Published: 17 July 2018

\begin{abstract}
Both academia and industry are currently devoting many efforts to develop high gas barrier bioplastics as substitutes of traditional fossil-based polymers. In this view, this contribution presents a new biobased aromatic polyester, i.e., poly(propylene 2,5-thiophenedicarboxylate) (PPTF), which has been compared with the furan-based counterpart (PPF). Both biopolyesters have been characterized from the molecular, thermo-mechanical and structural points of view. Gas permeability behavior has been evaluated with respect to $100 \%$ oxygen, carbon dioxide and nitrogen at $23{ }^{\circ} \mathrm{C}$. In case of $\mathrm{CO}_{2}$ gas test, gas transmission rate has been also measured at different temperatures. The permeability behavior at different relative humidity has been investigated for both biopolyesters, the thiophen-containing sample demonstrating to be better than the furan-containing counterpart. PPF's permeability behavior became worse than PPTF's with increasing RH, due to the more polar nature of the furan ring. Both biopolyesters under study are characterized by superior gas barrier performances with respect to PEF and PET. With the simple synthetic strategy adopted, the exceptional barrier properties render these new biobased polyesters interesting alternatives in the world of green and sustainable packaging materials. The different polarity and stability of heterocyclic rings was revealed to be an efficient tool to tailor the ability of crystallization, which in turn affects mechanical and barrier performances.
\end{abstract}

Keywords: poly(propylene 2,5-thiophenedicarboxylate); poly(propylene 2,5-furandicarboxylate); biopolyesters; thermal properties; mechanical properties; gas barrier properties

\section{Introduction}

Food packaging plays a key role in the protection and preservation of all types of foods. Petrochemical plastics have been largely used as packaging material due to economical abundance and good barrier properties towards $\mathrm{O}_{2}$, aroma compounds, tensile strength and tear strength. Meanwhile, they have some disadvantages, the major one being non-biodegradability, which results in environmental pollution. Due to the non-renewable nature and waste disposal problem of petroleum, bioplastics have gained increasing importance in the last years. In particular, there has been an increased interest in the last 10 years from the food packaging industry towards the development and application of bioplastics for food packaging. Despite the worldwide production of bioplastics being in 
consistent and constant increase, there are some disadvantages that limit their use in the present time: First of all, the uneconomic feasibility of bioplastics in contrast to traditional packaging; and more importantly, the use of land for the production of bioplastics is a major hurdle in the success of bioplastic functionality. Moreover, the properties of certain bioplastics are unsatisfactory, reducing their use as films in food packaging applications. Poly(lactic acid) (PLA), for example, is characterized by thermal instability, difficult heat sealability, brittleness, low melt strength, high water vapor and oxygen permeability [1]. Other starch- and cellulose-based packaging materials due to their hydrophilic nature possess low water vapor barrier, which is responsible for poor processability, brittleness, vulnerability to degradation, limited long-term stability and poor mechanical properties [2]. In case of Poly(hydroxyalkanoate) (PHA) and poly(hydroxybutyrate (PHB), stiffness, brittleness (due to high glass transition and melting temperatures), thermal instability and poor impact resistance also restrict their applications in food packaging [3]. The aforementioned drawbacks have stimulated research into finding solutions for improving the functionality of bioplastics and developing new bioplastics.

As reported from Papageorgiou [4], vegetable feedstocks such as sugars, vegetable oil, organic acids and glycerols could be used as starting monomers for the production of new polymer. One of the most important example of monomer extracted from natural resources, such as carbohydrates and lignin, is the aromatic monomer 2,5-furan dicarboxylic acid (FDCA). The success of this biobased building block is mostly due to the synthesis of poly(ethylene 2,5-furanoate) (PEF), considered the most credible bio-based alternative to poly(ethylene terephthalate) (PET). PEF possesses superior physic/mechanical and barrier properties compared to PET [5-8]. Furthermore, recent studies have demonstrated the enzymatic degradability of PEF and PET, opening up new possibilities in eco-friendly industrial depolymerization processes for recycling purposes [9-11]. In particular, a recent work demonstrated the degradability of PEF by cutinase from Humicola insolens, leading to complete polymer solubilisation in $72 \mathrm{~h}$ of incubation [11].

For these reasons, research interest has been extended to other furan-based polyesters prepared by 2,5-furandicarboxylic acid and different glycols that showed very smart barrier properties [12,13].

This year, we proposed a novel homopolymer with outstanding gas barrier properties as alter egos of FDCA-based polyesters, i.e., poly(butylene 2,5-thiophenedicarboxylate) (PBTF) [14,15]. Both starting materials, 2,5-thiophenedicarboxylic acid (TFDCA) and 1,4-butanediol (BD), can be derived from renewable resources, thus obtaining a fully biobased polymer. TFDCA is indeed industrially produced from the reaction of adipic acid with thionyl chloride [16,17]. In turn, adipic acid can be obtained from glucaric or muconic acid [18].

In light of the scenario described above, in the present contribution, poly(propylene 2,5-thiophendicarboxylate) (PPTF) has been synthesized for the first time, and characterized from the molecular, thermal, diffractometric, mechanical and barrier behavior points of view. Poly(propylene 2,5-furandicarboxylate) (PPF) has been also prepared in order to evaluate the effect of different heterocyclic five-membered aromatic ring on the final biopolyester properties. Both polyesters under study are $100 \%$ biobased, the 1,3-propanediol being obtainable from bioconversion of glycerol [19].

To the best of our knowledge, no studies regarding the effect of substitution of the furan ring with thiophene have been described in the literature.

\section{Materials and Methods}

\subsection{Materials}

TFDCA (97\%) was purchased from TCI (Tokyo, Japan), whereas FDCA (98\%) from CHEMOS GmbH \& Co. K (Regenstauf, Germany). 1,3-propanediol (1,3-PD), hexafluoro-2-propanol, chloroform, methanol, BD (99\%), titanium tetrabutoxide (TBT, 97\%) and titanium isopropoxide (TTIP, 97\%) were obtained from Sigma Aldrich (St. Louis, MO, USA). TBT and TTIP were both distilled before use, while other products were used as received. 


\subsection{Polyester Synthesis}

PPTF was prepared by two-step melt polycondensation by reacting TFDCA (15.2 $\mathrm{g}, 0.088 \mathrm{moL})$ with PD $(19.9 \mathrm{~g}, 0.262 \mathrm{moL})$ in the presence of $200 \mathrm{ppm} / \mathrm{g}_{\text {polymer }}$ of TBT and $200 \mathrm{ppm} / \mathrm{g}_{\text {polymer }}$ of TTIP. A $200 \mathrm{~mL}$ glass reactor was placed in a silicon oil bath and the reaction mixture was stirred at $100 \mathrm{rpm}$ by a two-bladed centrifugal stirrer connected to an overhead motor (IKA-Werke GmbH \& Co., Staufen, Germany). Nitrogen flow was applied and the temperature was set to $170{ }^{\circ} \mathrm{C}$. When more than $90 \%$ of the water produced during esterification was distilled off (about $3 \mathrm{~h}$ ), pressure and temperature were gradually reduced to $0.1 \mathrm{mbar}$ and increased to $200{ }^{\circ} \mathrm{C}$, respectively. Polymerization was stopped when constant torque was measured (4 additional hours). As far as PPF is concerned, a molar diacid/glycol ratio of 1:7 and antimony trioxide (10.6 mg per gram of final theoretical polymer) were employed. The glycol was used in large excess in order to enhance FDCA solubilization. All the reagents and catalysts were loaded into the polymerization reactor simultaneously and constantly mixed by a mechanical stirrer. After around $30 \mathrm{~min}$, the mixture turned out transparent indicating the solubilization of the acid in the glycol. For the subsequent two hours, the temperature was fixed at $180^{\circ} \mathrm{C}$ under controlled nitrogen flow in presence of a reflux condenser, to limit the leakage of BD from the reaction medium. Then, the temperature was raised at $200^{\circ} \mathrm{C}$ and the reflux condenser taken off $\left(1 \mathrm{~h}\right.$ and half). In the second stage, the temperature was increased until $220^{\circ} \mathrm{C}$, while the pressure was gradually reduced to $0.1 \mathrm{mBar}$. This stage was stopped when the torque reached a constant value ( $2 \mathrm{~h}$ and half).

The as-synthesized polymers were purified through dissolution in a mixture hexafluoro-2-propanol/chloroform and precipitation in methanol. The purified polymers, in the form of white floccules, were dried at $30^{\circ} \mathrm{C}$ under vacuum to constant weight. Thin films of about $150 \mu \mathrm{m}$ of thickness, were obtained by compression molding using a Carver press. Purified polymer was melted $30{ }^{\circ} \mathrm{C}$ above their melting temperature and kept for $2 \mathrm{~min}$ at a pressure of 5 tons $/ \mathrm{m}^{2}$. Lastly, films were cooled to RT in press by tap water.

Film thickness was determined by Sample Thickness Tester DM-G (Brugger Feinmechanik GmbH, Munich, Germany). Reported value represents the mean thickness of three experimental tests, each run on 10 different points of the polymer film surface at RT.

\subsection{Molecular, Thermal and Structural Characterization}

Polymer structure was checked by ${ }^{1} \mathrm{H}-\mathrm{NMR}$ spectroscopy at RT. A Varian Inova $400-\mathrm{MHz}$ (Palo Alto, CA, USA) was used for the measurements.

Molecular weight was determined by gel-permeation chromatography (GPC) at $30{ }^{\circ} \mathrm{C}$ with a 1100 HPLC system equipped with PLgel 5- $\mu$ m MiniMIX-C column ((Santa Clara, CA, USA). A UV-detector (Santa Clara, CA, USA) was employed. A Hexafluoro-2-propanol/chloroform mixture $(5: 95 \mathrm{v} / \mathrm{v})$ was used as eluent with a $0.3 \mathrm{~mL} / \mathrm{min}$ flow. A molecular weight calibration curve was obtained with polystyrene standards in the molecular weight range 800-100,000 g/moL.

TGA was carried out under nitrogen atmosphere by means of a Perkin Elmer TGA7 apparatus (Waltham, MA, USA). Gas flow of $30 \mathrm{~mL} / \mathrm{min}$ and heating scan of $10^{\circ} \mathrm{C} / \mathrm{min}$ were used for the analysis.

A Perkin Elmer DSC6 (Waltham, MA, USA) was used for the calorimetric measurements. Weighed samples were encapsulated in aluminum pans and heated to about $40{ }^{\circ} \mathrm{C}$ above fusion temperature at a rate of $20^{\circ} \mathrm{C} / \mathrm{min}$ (first scan), held there for $3 \mathrm{~min}$, and then quenched to $-40{ }^{\circ} \mathrm{C}$. Finally, they were reheated from $-10{ }^{\circ} \mathrm{C}$ to a temperature well above the melting at a heating rate of $20{ }^{\circ} \mathrm{C} / \mathrm{min}$ (second scan).

X-ray diffraction (XRD) patterns of polymeric films were carried out by using a PANalytical $X^{\prime}$ PertPro diffractometer (Almelo, The Netherlands) equipped with a copper anode $(\lambda=0.15418 \mathrm{~nm})$ and a fast solid state $X^{\prime}$ Celerator detector (Almelo, The Netherlands). Data were collected in the 3-60 $2 \theta$ interval (collecting time $100 \mathrm{sec} / \mathrm{step}, 0.10^{\circ}$ / step). The indices of crystallinity $\left(\chi_{\mathrm{c}}\right)$ were evaluated from the XRD profiles by the ratio between the crystalline diffraction area $\left(\mathrm{A}_{c}\right)$ and the total area of the diffraction profile $\left(A_{t}\right), \chi_{c}=A_{c} \times 100 / A_{t}$. The crystalline diffraction area has been obtained from the 
total area of the diffraction profile by subtracting the amorphous halo. The amorphous was modeled as bell shaped peak baseline. The non-coherent scattering was previously subtracted.

The in situ XRD patterns were collected by means of an Anton Paar (Graz, Austria) TTK450 hot stage mounted inside the diffractometer $\left(5-40^{\circ} 2 \theta\right.$ interval; collecting time $\left.40 \mathrm{sec} / \mathrm{step}, 0.10^{\circ} / \mathrm{step}\right)$.

\subsection{Mechanical Properties}

Tensile measurements were carried out on rectangular films ( $5 \mathrm{~mm}$ wide and $0.2 \mathrm{~mm}$ thick) with a crosshead speed of $10 \mathrm{~mm} / \mathrm{min}$ by using a Instron 4465 tensile testing machine (Norwood, MA, USA), equipped with a rubber grip and a $100 \mathrm{~N}$ load cell. A preload of $1 \mathrm{MPa}$ was applied to each specimen prior to testing. At least five replicates were run and the results are provided as the average \pm standard deviation.

The film thickness was determined using a Digital Dial Indicator (MarCator 1086 type, Mahr GmbH, Esslingen, Germany), connected to a PC, using the Sample Thickness Tester DM-G software. The reading was made measuring a minimum, a maximum and an average value. The thickness value is expressed in micron, with a resolution of $0.001 \mu \mathrm{m}$. The reported results represent the mean value thickness of three experimental tests run at 10 different points on the polymer film surface at room temperature. The film thickness was approximately of 200 and 120 micron for PPF and PPTF, respectively.

\subsection{Water Contact Angle Measurements}

Static contact angle measurements were performed on polymer films by using a KSV CAM101 instrument (KSV Instruments, Helsinki, Finland) by recording the side profiles of deionized water drops for image analysis. Eight drops were observed on different areas for each film, and water contact angles (WCA) were reported as the average value standard deviation.

\subsection{Gas Transport Measurements}

The determination of the gas barrier behavior was performed by a manometric method using a Permeance Testing Device, type GDP-C (Brugger Feinmechanik, GmbH, München, Germany), according to ASTM 1434-82 (Standard test Method for Determining Gas Permeability Characteristics of Plastic Film and Sheeting), DIN 53536 in compliance with ISO/DIS 15 105-1 and according to Gas Permeability Testing Manual (Registergericht München HRB 77020, Brugger Feinmechanik GmbH).

After a preliminary high vacuum desorption of the lower analysis chamber, the upper chamber was filled with the gas test, at ambient pressure. A pressure transducer, set in the lower chamber, records continuously the increasing of gas pressure as a function of the time. The gas transmission rate (GTR, expressed in $\mathrm{cm}^{3} \cdot \mathrm{m}^{-2} \cdot \mathrm{day}^{-1} \cdot \mathrm{bar}^{-1}$ ) was determined considering the increase in pressure in relation to the time and the volume of the device. All measurements have been carried out at room temperature of $23^{\circ} \mathrm{C}$. The operative conditions were: Gas stream of $100 \mathrm{~cm}^{3} \cdot \mathrm{min}^{-1} ; 0 \% \mathrm{RH}$ of gas test, food grade; sample area of $78.5 \mathrm{~cm}^{2}$ (standard measurement area). Films were analyzed at a temperature of $8,15,23$ and $38^{\circ} \mathrm{C}$. Gas transmission measurements were performed at least in triplicate and the mean value is presented. Method A was used for the analysis, as just reported in the literature $[20,21]$, with evacuation of up/lower chambers. Sample temperature was sets by an external thermostat HAAKE-Circulator DC10-K15 type (Thermo Fischer Scientific, Waltham, MA, USA).

The transport phenomena background followed in the experiment is well described in literature, with a full description of the mathematical equation and interpretation [22].

\subsection{Relative Humidity}

According to the procedure reported on the Gas Permeability Testing Manual [21], the analyses were performed at two relative humidities $(\mathrm{RH})$ obtained with saturated saline solutions:

- Standard Atmosphere, $23{ }^{\circ} \mathrm{C}, 85 \%$ of $\mathrm{RH}$, with saturated $\mathrm{KCl}$ solution; 
- $\quad$ Tropical Climate, $38^{\circ} \mathrm{C}, 90 \% \mathrm{RH}$, with saturated $\mathrm{KNO}_{3}$ solution, according to the DIN 53122 part 2 norm.

A round paper filter (Macherey-Nagel 85/70 BF 70 mm diameter, Düren, Germany) was inserted in the humid part of the top permeation cell, humidified with the desired saturated saline solution. Method $\mathrm{C}$ was used, with gas flow blocked onto the test specimen during evacuation. In this manner, the test gas was humidified inside the permeation cell. This method evacuates only the area of the bottom part of the sample while on the top part of the test specimen, with the humidified gas, the normal ambient pressure was applied.

\section{Results and Discussion}

\subsection{Molecular Characterization}

The as-prepared samples appeared as yellowish hard solid materials; the purified ones were white floccules. Their chemical structures are shown in Figure 1: As can be seen, the two homopolymers display a similar chemical structure, being both aromatic polyesters with same glycol sub-unit, although differing for the aromatic acid sub-unit, containing a furan ring in the case of PPF, and a thiophene one in PPTF.

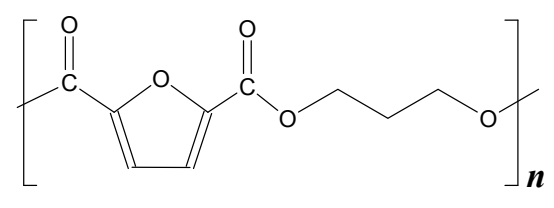

$P P F$

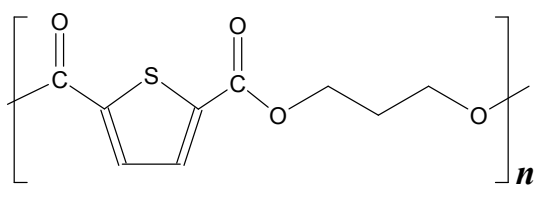

PPTF

Figure 1. Poly(propylene 2,5-furandicarboxylate) (PPF) and poly(propylene 2,5-thiophendicarboxylate) (PPTF) chemical structure.

The two heteroaromatic five-membered rings are characterized by some differences, first of all, the resonance energy has a different value: $6.2 \mathrm{Kcal} / \mathrm{mole}$ for furan and $29.1 \mathrm{Kcal} / \mathrm{mole}$ for thiophene, respectively. The resonance stabilization of heteroaromatic molecules depends on several factors, which arise from the atomic features of the heteroatom and result in different molecular properties. The ability of one of the heteroatom's non-bonding electron pairs to participate in the aromatic $\pi$-system is critical. Oxygen, being highly electronegative, shares its non-bonding electron pair less willingly than sulfur. Sulfurs' lower electronegativity, a result of its larger size and hence softness, permits greater participation of its non-bonding electron pair to the aromatic $\pi$-system. Therefore, the furan ring is the least aromatic, because of the highest electronegativity of oxygen. Analogously, the electronegative character of the heteroatoms determines a dipolar moment on the ring, the negative pole being located at the heteroatom. Once again, the dipole moments of furan and thiophene are different and function of the heteroatom electronegativity: The higher the electronegativity, the higher the dipole moment (Figure 2).

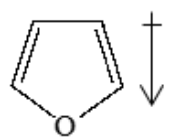

$0.7 \mathrm{D}$<smiles>[C+]1=CC=CS1</smiles>

$0.51 \mathrm{D}$

Figure 2. Dipole moment vector of furan and thiophene rings.

As far as the two polyesters under investigation are concerned, ${ }^{1} \mathrm{H}-\mathrm{NMR}$ analysis confirmed the expected structure (Figure 3) with no impurities in the spectrum. Both polymers are characterized by high and similar molecular weight and by same narrow polydispersity index (Table 1), proving that optimized reaction conditions were achieved. 


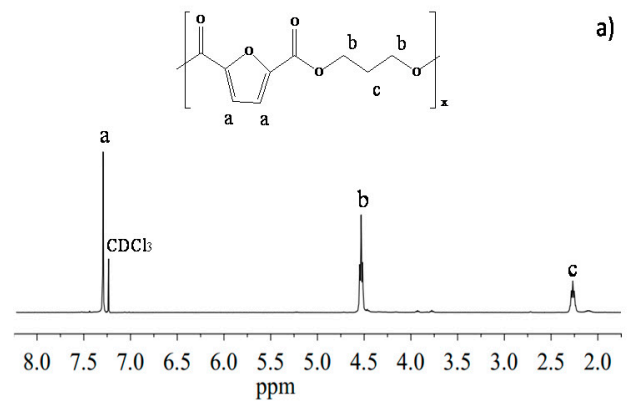

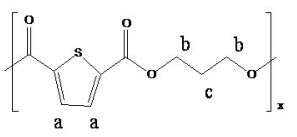

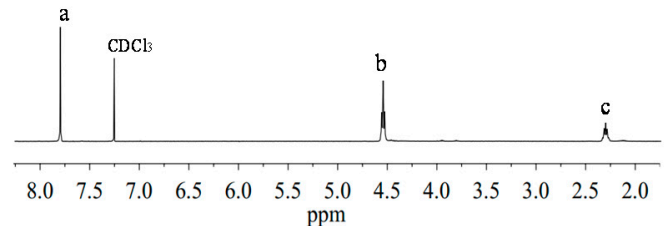

Figure 3. ${ }^{1} \mathrm{H}-\mathrm{NMR}$ spectrum of: (a) PPF; (b) PPTF with resonance assignments.

Table 1. Molecular, thermal and mechanical characterization data for PPF and PPTF.

\begin{tabular}{|c|c|c|c|c|}
\hline & \multicolumn{2}{|c|}{ PPF } & \multicolumn{2}{|c|}{ PPTF } \\
\hline \multicolumn{5}{|c|}{ MOLECULAR CHARACTERIZATION } \\
\hline $\mathrm{M}_{\mathrm{n}}(\mathrm{g} / \mathrm{moL})$ & \multicolumn{2}{|c|}{30,000} & \multicolumn{2}{|c|}{26,300} \\
\hline $\mathrm{D}$ & \multicolumn{2}{|c|}{2.3} & \multicolumn{2}{|c|}{2.3} \\
\hline WCA $\left(^{\circ}\right)$ & \multicolumn{2}{|c|}{$90 \pm 3$} & \multicolumn{2}{|c|}{$94 \pm 3$} \\
\hline \multicolumn{5}{|c|}{ THERMAL CHARACTERIZATION } \\
\hline \multicolumn{5}{|c|}{ Thermogravimetric analysis } \\
\hline $\mathrm{T}_{\text {onset }}\left({ }^{\circ} \mathrm{C}\right)$ & \multicolumn{2}{|c|}{360} & \multicolumn{2}{|c|}{373} \\
\hline $\mathrm{T}_{\max }\left({ }^{\circ} \mathrm{C}\right)$ & \multicolumn{2}{|c|}{387} & \multicolumn{2}{|c|}{396} \\
\hline \multicolumn{5}{|c|}{ Differential scanning calorimetry } \\
\hline \multicolumn{5}{|c|}{ 1st scan } \\
\hline & powder & film & powder & film \\
\hline $\mathrm{T}_{\mathrm{m}}\left({ }^{\circ} \mathrm{C}\right)$ & 165 & 169 & 183 & 184 \\
\hline$\Delta \mathrm{H}_{\mathrm{m}}(\mathrm{J} / \mathrm{g})$ & 26 & 7 & 39 & 37 \\
\hline $\mathrm{T}_{\mathrm{g}}\left({ }^{\circ} \mathrm{C}\right)$ & 56 & 52 & 45 & 40 \\
\hline$\Delta \mathrm{C}_{\mathrm{p}}^{\mathrm{g}}\left(\mathrm{J} / \mathrm{g}^{\circ} \mathrm{C}\right)$ & 0.278 & 0.361 & 0.128 & 0.229 \\
\hline $\mathrm{T}_{\mathrm{C}}\left({ }^{\circ} \mathrm{C}\right)$ & 119 & 138 & - & 161 \\
\hline$\Delta \mathrm{H}_{\mathrm{cc}}(\mathrm{J} / \mathrm{g})$ & 7 & 7 & - & 3 \\
\hline \multicolumn{5}{|c|}{ 2st scan } \\
\hline & powder & film & powder & film \\
\hline $\mathrm{T}_{\mathrm{m}}\left({ }^{\circ} \mathrm{C}\right)$ & - & - & 183 & 183 \\
\hline$\Delta \mathrm{H}_{\mathrm{m}}(\mathrm{J} / \mathrm{g})$ & - & - & 34 & 36 \\
\hline $\mathrm{T}_{\mathrm{g}}\left({ }^{\circ} \mathrm{C}\right)$ & 52 & 52 & 39 & 38 \\
\hline$\Delta \mathrm{C}_{\mathrm{p}}^{\circ}\left(\mathrm{J} / \mathrm{g}^{\circ} \mathrm{C}\right)$ & 0.361 & 0.359 & 0.315 & 0.227 \\
\hline $\mathrm{T}_{\mathrm{c}}\left({ }^{\circ} \mathrm{C}\right)$ & - & - & 104 & 101 \\
\hline$\Delta \mathrm{H}_{\mathrm{cc}}(\mathrm{J} / \mathrm{g})$ & - & - & 30 & 31 \\
\hline \multicolumn{5}{|c|}{ MECHANICAL CHARACTERIZATION } \\
\hline $\mathrm{E}(\mathrm{MPa})$ & \multirow{3}{*}{\multicolumn{2}{|c|}{$\begin{array}{c}1363 \pm 158 \\
31 \pm 3 \\
3 \pm 1\end{array}$}} & \multirow{3}{*}{\multicolumn{2}{|c|}{$\begin{array}{c}1419 \pm 165 \\
12 \pm 4 \\
2 \pm 0.5\end{array}$}} \\
\hline$\sigma_{\mathrm{B}}(\mathrm{MPa})$ & & & & \\
\hline$\varepsilon_{\mathrm{B}}(\%)$ & & & & \\
\hline \multicolumn{5}{|c|}{ GAS PERMEABILITY CHARACTERIZATION AT $23{ }^{\circ} \mathrm{C}$ RH $0 \%$} \\
\hline $\mathrm{O}_{2}$-GTR & \multirow{3}{*}{\multicolumn{2}{|c|}{$\begin{array}{l}0.0224 \pm 3 \times 10^{-6} \\
0.0288 \pm 3 \times 10^{-6} \\
0.0157 \pm 6 \times 10^{-5}\end{array}$}} & \multirow{3}{*}{\multicolumn{2}{|c|}{$\begin{array}{c}0.0202 \pm 14 \times 10^{-5} \\
0.0243 \pm 13 \times 10^{-5} \\
0.0120 \pm 2 \times 10^{-5}\end{array}$}} \\
\hline $\mathrm{CO}_{2}$-GTR & & & & \\
\hline $\mathrm{N}_{2}$-GTR & & & & \\
\hline
\end{tabular}


It is worth highlighting the reagents were used as received and the adopted protocol is very close to industrial procedures for the preparation of polyesters. The synthesized polyesters were filmed by compression molding and rapid cooled in ice water.

As shown by the WCA data reported in Table 1, PPF film appeared to be more hydrophilic than the PPTF one, in agreement with its higher dipole moment.

\subsection{Thermal Characterization}

Afterwards PPF and PPTF samples have been subjected to thermogravimetric analysis (TGA) under nitrogen flux. The temperatures relative to the degradation onset $\mathrm{T}_{\text {onset }}$ and to the maximum weight loss rate $T_{\max }$ have been reported in Table 1, whereas the TGA curves together with the corresponding derivatives are shown in Figure 4: Both polyesters displayed good thermal stability, the degradation process occurring in one step, with a residual mass of $6 \%$ at $800{ }^{\circ} \mathrm{C}$. Anyway, PPTF appeared to be more thermally stable than PPF. This result can be ascribed as due to: (i) the higher resonance energy, (ii) $\mathrm{p}$ to $\mathrm{d} \pi$-back bonding and (iii) lack of ring strain because of the longer $\mathrm{C}-\mathrm{S}$ bond for PPTF.

The main thermal transition data of both powder samples (labeled as PPF_P and PPTF_P) and polymer films (labeled as PPF_F and PPTF_F) are reported in Table 1.

From the data reported in Table 1 and from the DSC curves of Figure 5, one can see that the two homopolymers in forms of powder displayed identical phase behavior: both were indeed semicrystalline samples, even though PPF was able to crystallize during heating scan once $T_{g}$ is exceeded $\left(\Delta \mathrm{H}_{\mathrm{cc}}<\Delta \mathrm{H}_{\mathrm{m}}\right)$.

The higher crystallinity degree of PPTF indicates a higher crystallizing ability with respect to PPF.

As to the glass transition phenomenon, both $\mathrm{T}_{\mathrm{g}}$ values are above room temperature, indicating that in both polymers a glassy amorphous phase is present. $T_{g, P P F}>T_{g, P P T F}$ despite the higher crystallinity degree of PPTF, due to stronger interchain interactions present in PPF because of higher electronegativity of oxygen atoms. The $\mathrm{T}_{\mathrm{g}} \mathrm{s}$ of the powders are higher than the corresponding films, as expected considering their higher crystallinity degree, due to solvent induced crystallization.

The higher melting temperature of PPTF can be associated with a crystalline phase characterized by a higher degree of perfection, due to both the higher mobility of macromolecular chains and the higher aromaticity of thiophene rings, which favors the chain folding.

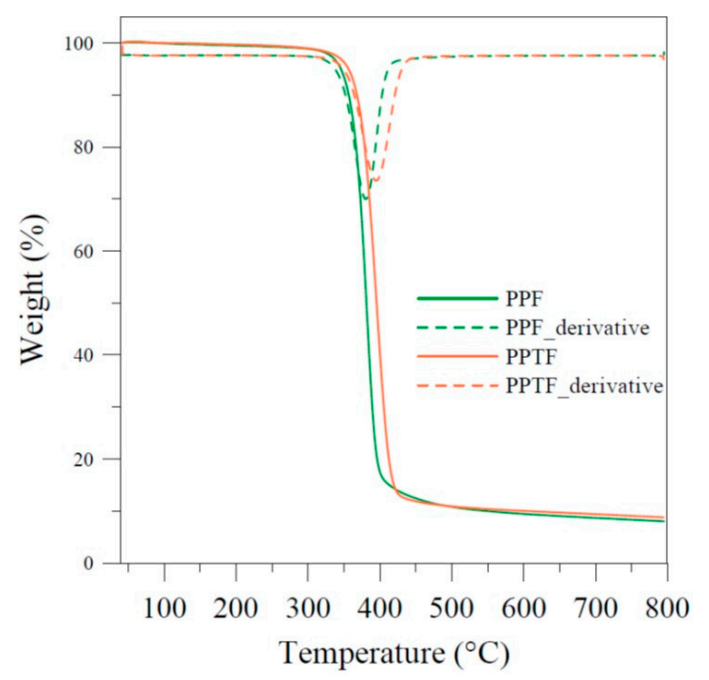

Figure 4. Thermogravimetric curve (solid line) and corresponding derivative (dashed line) under nitrogen flow for PPF and PPTF. 

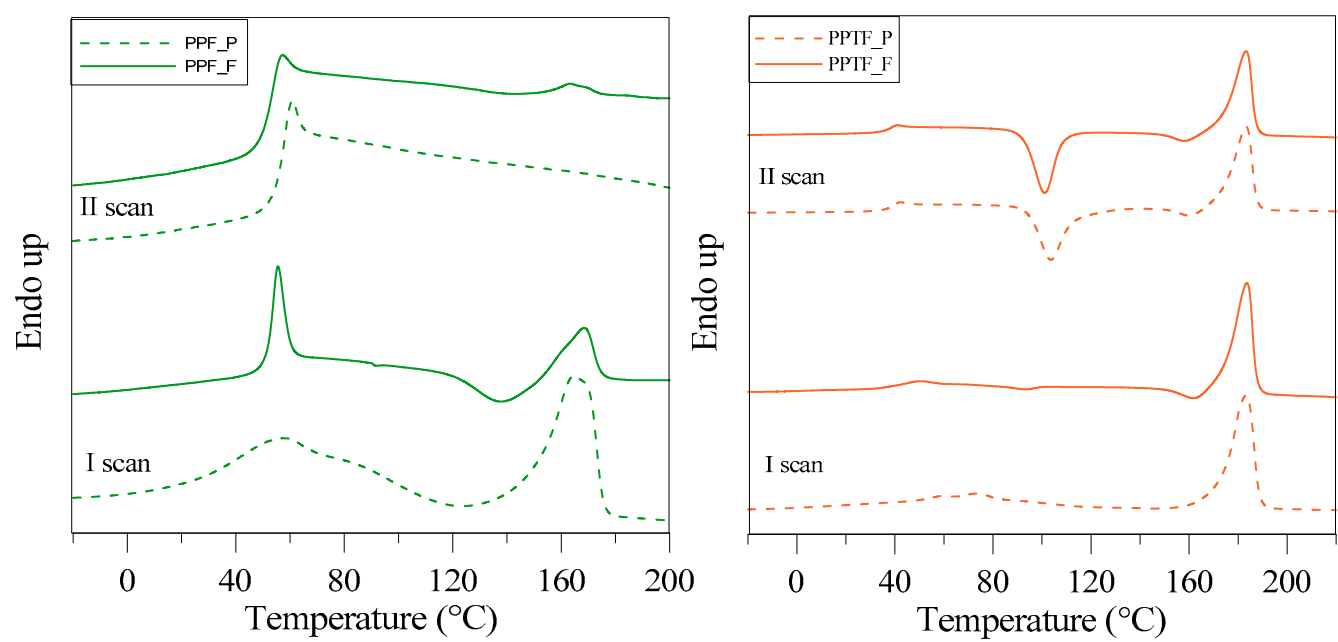

Figure 5. Calorimetric traces of PPF and PPTF powder and film $\left(20^{\circ} \mathrm{C} / \mathrm{min}\right): 1$ st scan and 2 nd scan after melt quenching.

As a matter of fact after melt quenching, the two polyesters, independent of whether they are in film or powder form, are characterized by a different phase behavior: PPF is completely amorphous, as evidenced by the corresponding DSC trace exclusively showing the baseline deviation associated to the glass transition phenomenon, whereas PPTF is semicrystalline. In this last case, the DSC trace evidenced the glass transition phenomenon followed by a cold crystallization peak and a melting peak at higher temperature. The heat of crystallization is however lower than the heat of fusion indicating that the material cannot be vetrified in a completely amorphous state by quenching. The behavior after melt quenching confirmed the higher crystallizing ability of PPTF with respect to PPF. The $\mathrm{T}_{\mathrm{g}}$ values of 2 nd scan are in line with those of the 1st scan, the $T_{g}$ of PPTF being lower than that of PPF.

\subsection{Diffractometric Characterization}

X-ray diffraction (XRD) measurements were carried out to investigate the nature of the crystal phase. Collected patterns are displayed in Figure 6. PPTF powder sample showed most significant peaks at $2 \theta$ values of $9.2^{\circ}, 16.3^{\circ}, 17.9^{\circ}, 22.5^{\circ}, 24.1^{\circ}, 26.6^{\circ}(d=9.6,5.4,4.9,3.9,3.7,3.3 \AA)$ and crystallinity index $X_{c}=46( \pm 3) \%$. PPTF film was characterized by reflections at $2 \theta$ of $9.3^{\circ}, 16.3^{\circ}, 23.3^{\circ}, 25.6^{\circ}(d=9.5$, $5.4,3.8,3.5 \AA)$ and $X_{c}=43( \pm 3) \%$. The peak positions and shape of the two patterns were different enough to assign them to different crystal phases, hereinafter named $\alpha$-PPTF in case of powder sample, and $\beta$-PPTF for film sample.

As shown in Figure 6, PPF film after preparation shows a very poor crystallinity $\left(X_{c}=3( \pm 2) \%\right)$, but the thermal treatment at $110{ }^{\circ} \mathrm{C}$ for $45 \mathrm{~min}$. provoked a significant increase in crystallinity $\left(X_{c}=31\right.$ $( \pm 3) \%)$. It became very similar to the one of powder sample $\left(X_{c}=37( \pm 3) \%\right)$. The XRD patterns of PPF, either in powder or film after annealing, were similar and can be attributed to the same (a unique) crystal phase. This had main reflections at $10.2^{\circ}, 16.4^{\circ}, 19.1^{\circ}, 22.6^{\circ}, 25.0^{\circ}, 28.6^{\circ}$ (corresponding to $d=8.7,5.4,4.6,3.9,3.6,3.1 \AA$ ). XRD analysis evidenced that the PPF sample is characterized by a lower degree of crystallinity, in perfect agreement with calorimetric results.

The thermal stability of the two different crystal phases present in PPTF powder and film samples were checked by in situ XRD measurements (see Figure 7). During the 1st scan process both samples showed their own crystal phase up to melting, no transformation of a phase in the other by solid-solid transition being appreciated. On the contrary, as pointed out by the patterns collected during 2nd scan, after melt quenching, the powder sample also crystallized according to the $\beta$-form, suggesting that $\beta$ crystal phase could be the more stable one. 


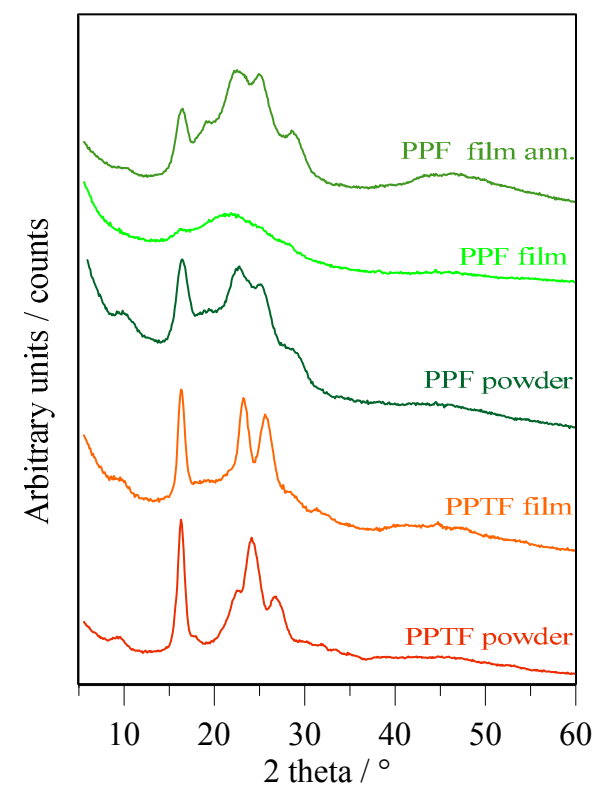

Figure 6. X-ray diffraction profiles of PPTF powder, PPTF film, PPF powder, PPF film and PPF film after annealing for $45 \mathrm{~min}$. at $110^{\circ} \mathrm{C}$.
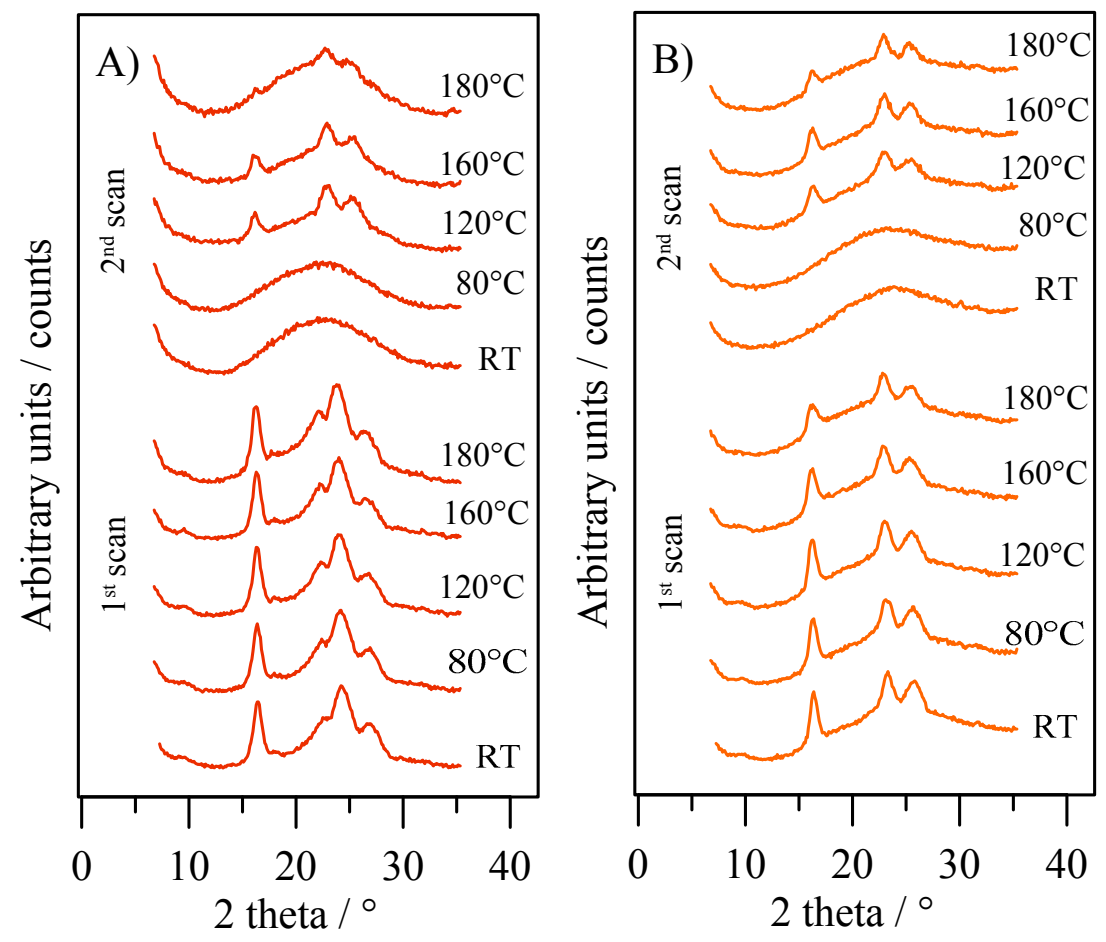

Figure 7. XRD patterns collected in situ at the indicated temperatures for PPTF powder (A) and PPTF film (B).

\subsection{Mechanical Characterization}

The results of tensile tests are reported in Table 1 . The slightly higher elastic modulus of PPTF can be explained on the basis of the crystalline phase present in this sample; the stress at break of PPF is, on the contrary, 2.5 times higher than that of PPTF because of its higher $\mathrm{T}_{g}$ value. Lastly, the elongation at break for the two samples was very similar. No significant effect of kind of ring on mechanical 
properties was thus evidenced. Moreover, the two polyesters showed similar characteristics, i.e., very high elastic modulus and brittle fracture, to that of PEF.

\subsection{Gas Permeability Characterization}

The barrier properties have been evaluated on respect three different dry gases, normally used for food packaging application, i.e., $\mathrm{N}_{2}, \mathrm{O}_{2}$ and $\mathrm{CO}_{2}$. The GTR values normalized for the sample thickness and measured at $23{ }^{\circ} \mathrm{C}$ and at $0 \%$ of humidity are collected in Table 1 : both polymers under study are characterized by outstanding barrier performances, comparable to that of PBTF [14] and superior to PEF ones [6,7].

The outstanding barrier properties of furan-based polymers are also supported by structural and dynamical studies showing the hindering of ring flipping [5] and the limited subglass local dynamics [23] imparted by furanic moiety. In addition, as suggested by Araujo et al., the ability of stopping the gas passage is also due to the establishment of $\mathrm{C}-\mathrm{H} \cdots \mathrm{O}$ interactions among adjacent polymer chain segments. The authors also state that the amount of intermolecular $\mathrm{C}-\mathrm{H} \cdots \mathrm{O}$ contacts is particularly favored when FDCA subunits are in the syn conformation, as in the crystalline PEF lattice [24]. The syn/anti conformations ratio also depends on the glycol methylene group number. We can hypothesize that the presence of an additional $\mathrm{CH}_{2}$ group in the PPF glycol subunit with respect to PEF, can favor the syn conformation of FDCA and consequently increase the $\mathrm{C}-\mathrm{H} \cdots \mathrm{O}$ interactions, improving the barrier properties of PPF.

Moreover, as can be evicted from the experimental data, for both the samples under study, $\mathrm{CO}_{2}$ is more permeable than $\mathrm{O}_{2}$ and $\mathrm{N}_{2}$, as observed for other similar polymers previously investigated $[25,26]$, due to diffusivity drop and solubility increment with decreasing permeant size (molecular diameter of $\mathrm{CO}_{2} 3.4 \AA$, oxygen molecular diameter $3.1 \AA$ and nitrogen molecule diameter $2.0 \AA$, respectively) [27]. However, it is worth noting that the gas transmission rates to oxygen and carbon dioxide were not so different, analogously to PEF polyester previously investigated [7]. The polar character of furan and thiophene moieties determined a high affinity (high solubility) of $\mathrm{CO}_{2}$ gas molecules with polymer matrix.

Barrier properties with respect to PPF: This result can be explained considering that PPTF film is semicrystalline while PPF one is amorphous. As is well known from literature [28], several factors could influence the final barrier behavior of the materials, such as crystallinity, chain polarity, chain flexibility, molecular weight and distribution of molecular weight. In particular, the crystallinity plays a key role since the gases cannot diffuse and permeate in the crystalline phase, due to the restricted polymer chain mobility in this phase. In general, polymer crystals are impenetrable to gas molecules and consequently the polymers with the higher percentage of crystalline phase are the best barrier materials.

\subsubsection{Activation Energy}

As is well known, permeability depends on temperature according to an Arrhenius-type equation, well described in literature [20,29]. Gas transmission rate increases exponentially with the temperature and the activation energy $\left(E_{a}\right)$ is a measure of the energy required to start the permeation process. By plotting the LnGTR against the reciprocal temperature 1 / T expressed in $\mathrm{K}$, a linear curve is obtained. The activation energy is deduced by calculating the value of the slope $\left(-E_{a} / R\right)$ of the Arrhenius straight line, where $\mathrm{R}$ is the gas constant $(8.314 \mathrm{~J} / \mathrm{moL} \mathrm{K})$.

We evaluated the activation energy for $\mathrm{CO}_{2}$ gas test: Values of $32 \mathrm{KJ} / \mathrm{moL}$ and of $20 \mathrm{KJ} / \mathrm{moL}$ were determined for PPF and PPTF, respectively (with $\mathrm{R}^{2}=0.9$, for both samples), in good agreement with the value found by Burgess et al. for PEF $(23.7 \mathrm{KJ} / \mathrm{moL})$ [7]. The higher activation energy found for PPF can be correlated to the higher polarity of the furan ring compared to the thiophene one, which determines a higher affinity of carbon dioxide molecule for PPF. 


\subsubsection{Influence of Relative Humidity on the Gas Transmission Rate}

In order to explore a future application of PPTF and PPF as packaging materials, the effect of RH and temperature on the gas transmission was investigated. Figure 8 visualizes the measured values of the GTR with RH gradients of $85 \%$ at $23{ }^{\circ} \mathrm{C}$ and of $90 \%$ at $38{ }^{\circ} \mathrm{C}$ respectively. These conditions were chosen to describe the standard atmosphere and tropical ambient, respectively, as reported on the Gas Permeability Testing Manual [21].

The results showed that the GTR values of both PPF and PPTF films increased with increasing RH, in agreement with data described in literature for other polymers [29-31]. The water vapor molecules that goes through the polymer membrane can acts as plasticizer, giving rice to an increase in polymer free volume, with consequent higher gas permeability [30]. The effect is particularly evident in the case of nitrogen and oxygen, while in contrast being more modest for carbon dioxide. This result could be due to the higher affinity (solubility) of $\mathrm{CO}_{2}$ with both polymer matrices. It has to be reminded that furan rings, as well as thiophene ones, are polar moiety and carbon dioxide molecule is characterized by an induced dipole moment.

Table 2 collects the increment, expressed as in percentage terms, in respect to the value determined at 23 and $38^{\circ} \mathrm{C}$, respectively. At $23^{\circ} \mathrm{C}$, the major increments of GTR were recorded for PPF sample: this trend could be explained as due to the higher plasticizer effect of water in case of PPF. PPF macromolecular chains are indeed characterized by a higher polarity, in comparison to the ones of PPTF, as proved by the higher dipole moment associated to furan ring.
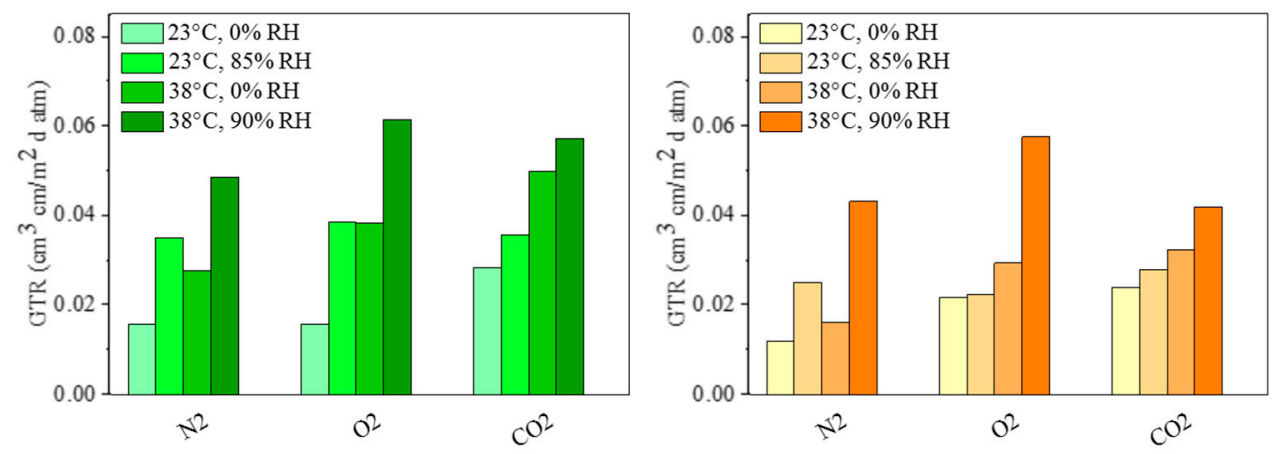

Figure 8. GTR at $23{ }^{\circ} \mathrm{C}$ and $38{ }^{\circ} \mathrm{C} 0 \% \mathrm{RH}$, at $23{ }^{\circ} \mathrm{C}$ and $85 \% \mathrm{RH}$, at $38{ }^{\circ} \mathrm{C}$ and $90 \% \mathrm{RH}$.

Consequently, PPTF film showed excellent moisture resistance.

An opposite result was obtained at $38^{\circ} \mathrm{C}$ : this temperature is very close to PPTF glass transition temperature. At this temperature, macromolecular cooperative motions start with a significant raise of free volume, and hence of frequency of successful gas diffusive jumps.

Table 2. Percent of GTR increment at $23{ }^{\circ} \mathrm{C}$ and $85 \%$ of $\mathrm{RH}$ and at $38{ }^{\circ} \mathrm{C}$ and $90 \%$ of $\mathrm{RH}$.

\begin{tabular}{ccccc}
\hline \multirow{2}{*}{ Gas } & \multicolumn{2}{c}{ PPF } & \multicolumn{2}{c}{ PPTF } \\
\cline { 2 - 5 } & $\mathbf{2 3}{ }^{\circ} \mathbf{C}, \mathbf{8 5} \mathbf{~ R H}$ & $\mathbf{3 8}{ }^{\circ} \mathbf{C}, \mathbf{9 0} \% \mathbf{R H}$ & $\mathbf{2 3}{ }^{\circ} \mathbf{C}, \mathbf{8 5} \% \mathbf{R H}$ & $\mathbf{3 8}{ }^{\circ} \mathbf{C}, \mathbf{9 0} \mathbf{~ R H}$ \\
\hline $\mathrm{N}_{2}$ & +123 & +75 & +109 & +167 \\
$\mathrm{O}_{2}$ & +77 & +60 & +3 & +96 \\
$\mathrm{CO}_{2}$ & +23 & +15 & +17 & +30 \\
\hline
\end{tabular}

\section{Conclusions}

Two $100 \%$ biobased aromatic polyesters were successfully synthesized by two-stage melt polycondensation, a solvent-free synthetic approach easily scaled up at industrial level. They differed in the diacid sub-unit, with the one of PPF containing the furan ring, in which the PPTF is replaced with thiophene. The thiophene ring is characterized by higher resonance energy, and lower dipole moment 
compared to the furan ring, which impacts on the solid-state properties: PPTF is indeed more thermally stable, its $\mathrm{T}_{\mathrm{g}}$ is lower, whereas the crystallizing ability is higher with respect to PPF. The different characteristics of the two ethero-aromatic five membered rings reflect on the barrier properties, which were outstanding for both biopolyesters, being even superior to PEF. Nevertheless, the measurements performed at different $\mathrm{RH}$ showed that the gas transmission increased with increasing $\mathrm{RH}$, the increment being more modest for PPTF at $23^{\circ} \mathrm{C}$, due to a lower plasticizer effect of water because of the lower polarity of thiophene ring compared to furan one. An opposite result was obtained at $38^{\circ} \mathrm{C}$, with PPF appearing more performant than PPTF. The temperature of $38^{\circ} \mathrm{C}$, which mimics tropical climate, is very close to PPTF's $\mathrm{T}_{\mathrm{g}}$ and therefore is where a significant increment of free volume occurs.

In conclusion, both biopolyesters here presented represent excellent candidates for sustainable packaging applications, PPTF being preferable in areas with a temperate climate, and PPF in tropical regions.

Author Contributions: N.L., V.S. and A.M. conceived and designed the experiments; G.G., M.S., M.G. and V.S. performed the experiments; N.L., M.G., M.S. and V.S. analyzed the data; N.L., V.S. and A.M. contributed to reagents/materials/analysis tools; N.L. wrote the paper.

Funding: This research received no external funding.

Acknowledgments: N.L., A.M. and M.S. acknowledge the Italian Ministry of University and Research. V.S. wish to thanks the "Piano della Ricerca di Ateneo 2016-2018", University of Catania, Italy, for financial support for gas barrier measurements.

Conflicts of Interest: The authors declare no conflict of interest.

\section{References}

1. Rhim, J.W.; Hong, S.I.; Ha, C.S. Tensile, water vapour barrier and antimicrobial properties of PLA/nanoclay composite films. Food Sci. Technol. 2009, 42, 612-617.

2. Cyras, V.P.; Commisso, M.S.; Mauri, A.N.; Vázquez, A. Biodegradable double-layer films based on biological resources: Polyhydroxybutyrate and cellulose. J. Appl. Polym. Sci. 2007, 106, 749-756. [CrossRef]

3. Modi, S.J. Assessing the Feasibility of Poly-(3-hydroxybutyrate-co-3-valerate) (PHBV) and Poly-(lactic acid) for Potential Food Packaging Applications. Master's Thesis, Ohio State University, Columbus, OH, USA, 2010.

4. Papageorgeou, G.Z;; Papageorgeou, D.G.; Tsanaktsis, V.; Bikiaris, D.N. Synthesis of the bio-based polyester poly(propylene 2,5-furan dicarboxylate). Comparison of thermal behavior and solid state structure with its terephthalate and naphthalate homologues. Polymer 2015, 62, 28-38. [CrossRef]

5. Burgess, S.K.; Leisen, J.E.; Kraftschik, B.E.; Mubarak, C.R.; Kriegel, R.M.; Koros, W.J. Chain Mobility, Thermal, and Mechanical Properties of Poly(ethylene furanoate) Compared to Poly(ethylene terephthalate). Macromolecules 2014, 47, 1383-1391. [CrossRef]

6. Burgess, S.K.; Karvan, O.; Johnson, J.R.; Kriegel, R.M.; Koros, W.J. Oxygen sorption and transport in amorphous poly(ethylene furanoate). Polymer 2014, 55, 4748-4756. [CrossRef]

7. Burgess, S.K.; Kriegel, R.M.; Koros, W.J. Carbon Dioxide Sorption and Transport in Amorphous Poly(ethylene furanoate). Macromolecules 2015, 48, 2184-2193. [CrossRef]

8. Burgess, S.K.; Mikkilineni, D.S.; Yu, D.B.; Kim, D.J.; Mubarak, C.R.; Kriegel, R.M.; Koros, W.J. Water sorption in poly(ethylene furanoate) compared to poly(ethylene terephthalate). Part 2: Kinetic sorption. Polymer 2014, 55, 6870-6882. [CrossRef]

9. Ferrario, V.; Pellis, A.; Cespugli, M.; Guebitz, G.M.; Gardossi, L. Nature Inspired Solutions for Polymers: Will Cutinase Enzymes Make Polyesters and Polyamides Greener? Catalysts 2017, 6, 205. [CrossRef]

10. Pellis, A.; Gamerith, C.; Ghazaryan, G.; Aortner, A.; Herrero Acero, E.; Guebitz, G.M. Ultrasound-enhanced enzymatic hydrolysis of poly(ethylene terephthalate). Bioresour. Technol. 2016, 218, 1298-1302. [CrossRef] [PubMed]

11. Weinberger, S.; Canadell, J.; Quartinello, F.; Yeniad, B.; Arias, A.; Pellis, A.; Guebitz, G.M. Enzymatic Degradation of Poly(ethylene 2,5-furanoate) Powders and Amorphous Films. Catalysts 2017, 7, 318. [CrossRef] 
12. Soccio, M.; Costa, M.; Lotti, N.; Gazzano, M.; Siracusa, V.; Salatelli, E.; Manaresi, P.; Munari, A. Novel fully biobased poly(butylene 2,5-furanoate/diglycolate) copolymers containing ether linkages: Structure-property relationships. Eur. Polym. J. 2016, 81, 397-412. [CrossRef]

13. Genovese, L.; Lotti, N.; Siracusa, V.; Munari, A. Poly(Neopentyl Glycol Furanoate): A Member of the Furan-Based Polyester Family with Smart Barrier Performances for Sustainable Food Packaging Applications. Materials 2017, 10, 1028. [CrossRef] [PubMed]

14. Guidotti, G.; Gigli, M.; Soccio, M.; Lotti, N.; Gazzano, M.; Siracusa, V.; Munari, A. Poly(butylene 2,5-thiophenedicarboxylate): An added value to the class of high gas barrier biopolyesters. Polymers 2018, 10, 167. [CrossRef]

15. Guidotti, G.; Gigli, M.; Soccio, M.; Lotti, N.; Gazzano, M.; Siracusa, V.; Munari, A. Ordered structures of poly(butylene 2,5-thiophenedicarboxylate) and their impact on material functional properties. Eur. Polym. J. 2018, in press.

16. Zhi, W.; Hu, Y.; Liang, M.; Liu, Y.; Li, J.; Yin, J.; Shi, Y. Solid-liquid equilibrium and thermodynamic of 2,5-thiophenedicarboxylic acid in different organic solvents. Fluid Phase Equilib. 2014, 375, 110-114. [CrossRef]

17. Yang, Y.; Zhang, Q.; Cao, C.; Cheng, L.; Shi, Y.; Yang, W.; Hu, Y. Solubility and solution thermodynamics of 2,5-thiophenedicarboxylic acid in (water + ethanol) binary solvent mixtures. Thermochim. Acta 2014, 592, 52-57. [CrossRef]

18. Polen, T.; Spelberg, M.; Bott, M. Toward biotechnological production of adipic acid and precursors from biorenewables. J. Biotechnol. 2013, 167, 75-84. [CrossRef] [PubMed]

19. Luckachan, G.E.; Pillai, C.K.S. Biodegradable polymers: A Review on recent trends and emerging perspectives. J. Polym. Environ. 2011, 19, 637-676. [CrossRef]

20. Siracusa, V. Food packaging permeability behavior: A report. Int. J. Polym. Sci. 2012, 1, 1-11. [CrossRef]

21. Gas Permeability Testing Manual; Registergericht Munchen HRB 77020; Brugger Feinmechanik GmbH: München, Germany, 2008.

22. Siracusa, V.; Ingrao, C. Correlation amongst gas barrier behaviour, temperature and thickness in BOPP films for food packaging usage: A lab-scale testing experience. Polym. Test. 2017, 59, 277-289. [CrossRef]

23. Genovese, L.; Soccio, M.; Lotti, N.; Munari, A.; Szymczyk, A.; Paszkiewicz, S.; Linares, A.; Nogales, A.; Ezquerra, T.A. Effect of chemical structure on the subglass relaxation dynamics of biobased polyesters as revealed by dielectric spectroscopy: 2,5-Furandicarboxylic acid vs. trans-1,4-cyclohexanedicarboxylic acid. Phys. Chem. Chem. Phys. 2018, 20, 15696-15706. [CrossRef] [PubMed]

24. Araujo, C.F.; Nolasco, M.M.; Ribeiro-Claro, P.J.A.; Rudić, S.; Silvestre, A.J.D.; Vaz, P.D.; Sousa, A.F. Inside PEF: Chain Conformation and Dynamics in Crystalline and Amorphous Domains. Macromolecules 2018, 51, 3515-3526. [CrossRef]

25. Genovese, L.; Gigli, M.; Lotti, N.; Gazzano, M.; Siracusa, V.; Munari, A.; Dalla Rosa, M. Biodegradable Long Chain Aliphatic Polyesters Containing Ether-Linkages: Synthesis, Solid-State, and Barrier Properties. Ind. Eng. Chem. Res. 2014, 53, 10965-10973. [CrossRef]

26. Guidotti, G.; Soccio, M.; Siracusa, V.; Gazzano, M.; Salatelli, E.; Munari, A.; Lotti, N. Novel Random PBS-Based Copolymers Containing Aliphatic Side Chains for Sustainable Flexible Food Packaging. Polymers 2017, 9, 724. [CrossRef]

27. Robertson, G.L. Chapter 4: Optical, Mechanical and Barrier Properties of Thermoplastics Polymers. In Food Packaging-Principles and Practice, 3rd ed.; Taylor \& Francis Group, CRC Press: Boca Raton, FL, USA, 2013; pp. 91-130. ISBN 978-1-4398-6242-1.

28. Jamshidian, M.; Tehrany, E.A.; Cleymand, F.; Leconte, S.; Falher, T.; Desobry, S. Effect of synthetic phenolic antioxidants on physical, structural, mechanical and barrier properties of poly lactic acid film. Carbohydr. Polym. 2012, 87, 1763-1773. [CrossRef]

29. Schmid, M.; Zillinger, W.; Muller, K.; Sangerlaub, S. Permeation of water vapour, nitrogen, oxygen and carbon dioxide through whey protein isolated based films and coatings-Permselectivity and activation energy. Food Packag. Shelf Life 2015, 6, 21-29. [CrossRef]

30. Vandewijngaarden, J.; Murariu, M.; Dubois, P.; Carleer, R.; Yperman, J.; Adriaensens, P.; Schreurs, S.; Lepot, N.; Peeters, R.; Buntinx, M. Gas permeability properties of Poly(3-hydroxybutyrate-co-3-hydroxyhexanoate). J. Polym. Environ. 2014, 22, 501-507. [CrossRef] 
31. Hedenqvist, M.S. Barrier Packging Materials. In Handbook of Environmental Degradation of Materials; William Andrew: Norwich, NY, USA, 2012; pp. 833-862.

(c)

(C) 2018 by the authors. Licensee MDPI, Basel, Switzerland. This article is an open access article distributed under the terms and conditions of the Creative Commons Attribution (CC BY) license (http:/ / creativecommons.org/licenses/by/4.0/). 